\title{
Relationships between Changes in Posterior Occlusal Support Status and Risk of Protein-energy Malnutrition among the Japanese Community- dwelling Elderly
}

\author{
Ayako Nonomura ${ }^{1}$, Kaname Nohno ${ }^{2 *}$ and Hiroshi Ogawa ${ }^{1}$ \\ ${ }^{1}$ Department of Preventive Dentistry, Niigata University Graduate School of Medical and Dental Sciences, Niigata, Japan \\ ${ }^{2}$ Department of Preventive Dentistry, Niigata University Medical and Dental Hospital, Niigata, Japan
}

*Corresponding author: Kaname Nohno, Department of Preventive Dentistry, Niigata University Medical and Dental Hospital, Niigata, Japan, Tel: +81252272858; Email: no2@dent.niigata-u.ac.jp

Received date: February 07, 2019; Accepted date: February 15, 2019; Published date: February 20, 2019

Copyright: (c) 2019 Nonomura A, et al. This is an open-access article distributed under the terms of the Creative Commons Attribution License, which permits unrestricted use, distribution, and reproduction in any medium, provided the original author and source are credited.

\begin{abstract}
Objective: Protein-Energy Malnutrition (PEM) among the elderly limits the daily activities and leads to a bedridden state. Oral health status in the elderly can be one of the PEM indicators. We aimed to assess the correlation between changes in posterior occlusal support status and the incidence of PEM over a 5-year period in the Japanese community-dwelling elderly.

Materials and Methods: Two hundred and seventy-two subjects aged 75 years in 2003 were followed up in 2008. Posterior occlusal support without dentures in 2003 and 2008 was categorized into one of three groups based on the number of occlusal support zones (OSZ) present. According to the Eichner's Index and changes in the values over 5 years, five groups were defined for the main exposure variables: 1) Complete: four OSZ remaining, 2) Moderate: one to three OSZ remaining, 3) Lost support: no OSZ remaining, 4) Early change: change from four to one to three OSZ, and 5) Late change: change from one to three to no OSZ. For the outcome variables, the rates of changes in protein intake, total energy intake, and BMI over 5 years were calculated and divided into two groups. The nutrition status for malnutrition was defined as A) IPE: the rates of changes in protein and total energy intake were less than or equal to the median and B) IPEB: the rates of changes in the three items were less than or equal to the median.
\end{abstract}

Results: Male subjects whose posterior OSZ decreased from four to one to three over 5 years had a significantly higher risk of IPE and IPEB than those in other groups (odds ratio: 4.0 for IPE and 4.3 for IPEB).

Conclusion: Male elderly participants who lost posterior occlusal support zones over 5 years experienced a decrease in protein intake and had an increased risk of PEM.

Keywords: Malnutrition; Protein-energy malnutrition; Occlusal support zone; Elderly

\begin{abstract}
Abbreviation
PEM: Protein-Energy Malnutrition; POSS: Posterior Occlusal Support Status; OSZ: Occlusal Support Zone; ADL: Activities of Daily Living; TMIG: Tokyo Metropolitan Institute of Gerontology; BMI: Body Mass Index; BDHQ: Brief-type self-administered Diet History Questionnaire; IPE: Insufficient Protein and Energy; IPEB: Insufficient Protein, Energy and BMI; ANOVA: Analysis Of Variance
\end{abstract}

\section{Introduction}

Malnutrition is a serious problem for the elderly and is associated with a prolonged stay in the hospital [1,2], an increased risk of falls [1], decreased physical function [2], and poorer quality of life [2]. The prevalence of nutritional problems, especially Protein-Energy Malnutrition (PEM), has been on the rise, affecting $1-15 \%$ of outpatients and 15\%-60\% of institutionalized elderly [3]. Agarwal E, et al. classified the three stages of food consumption as obtaining food, ingestion, and finally, digestion and absorption. They reported oral health problems such as missing teeth and ill-fitting dentures as factors affecting the ingestion stage [4]. Previous studies evaluated the relationship between oral health problems and nutrition intake based on the number of remaining and missing teeth [5-8], chewing function [9], periodontal disease [10], and occlusal status [11-15]. Kazuya M reported that factors related to the malnutrition of elderly individuals were aging effects, social factors, psychological factors, and disease factors [16]. Thus, Posterior Occlusal Support Status (POSS) can affect nutrition intake, leading to malnutrition. Most of the studies only indicated the relationships between POSS and malnutrition but did not clarify the effects of changes in POSS on nutrition intake. Accordingly, this study was aimed at assessing the association between changes in POSS and malnutrition over a 5-year period among Japanese community-dwelling elderly.

\section{Material and Methods}

The target population for this study was drawn from the Niigata study between 2003 and 2008. The Niigata cohort study was a community-based study initiated in 1998 to assess the relationship between general and oral health. At the beginning of the current study in 2003, questionnaires were sent to all 4542 Nigata citizens aged 70 
Citation: Nonomura A, Nohno K, Ogawa H (2019) Relationships between Changes in Posterior Occlusal Support Status and Risk of Proteinenergy Malnutrition among the Japanese Community-dwelling Elderly. Dentistry 9: 534. doi:10.4172/2161-1122.1000534

Page 2 of 7

years in 1998 to inform them of the purpose of the study and request their participation. The positive response rate was $81.4 \%(n=3695)$. Six hundred individuals (screened population) were randomly selected with approximately the same number of male and female participants. The subjects agreed to undergo medical and dental examination and signed consent forms regarding the protocol. The Ethics Committee of the Faculty of Dentistry, Niigata University reviewed and approved this protocol. In 2003, five years after the Niigata study was initiated, dental and medical examination, dietary assessment, and a questionnaire survey were conducted for the participants to obtain the baseline data. In 2008, at the follow-up survey, the same examinations were conducted. The subjects who participated in both the baseline and follow-up examinations were included in the data analysis.

\section{Dental examination}

The dental examination was conducted at the baseline and followup visits by four calibrated dentists. According to the results of the dental examinations, POSS without dentures at the baseline and follow-up visits was categorized into one of three groups based on the number of Occlusal Support Zones (OSZ) present in accordance with Eichner's Index, reflecting the occlusal contacts of the existing natural teeth or fixed prostheses in the premolar and molar regions [12,17,18 ]. The POSS criteria for the subjects were as follows:

(i) Group A (four OSZ: Eichner A1, A2, and A3)

(ii) Group B (one to three OSZ: B1, B2, and B3)

(iii) Group C (no OSZ: B4, C1, C2, and C3)

\section{Medical examination}

Blood samples were collected at the baseline and follow-up examinations. The bromocresol green method was used to measure the serum albumin level.

\section{Questionnaire and anthropometric evaluations}

A questionnaire survey regarding the participants' medical histories (diabetes mellitus, hypertension, and renal disease), education, and ADL was administered at the baseline and follow-up visits. The Tokyo Metropolitan Institute of Gerontology (TMIG) Index of Competence was used to assess Activities of Daily Living (ADL). Anthropometric evaluations and both weight and height were measured to calculate BMI.

\section{Dietary assessment}

Dietary assessment was conducted at the baseline and follow-up visits using a Brief-type self-administered Diet History Questionnaire (BDHQ). The BDHQ was developed for the general Japanese population, and its validity has been tested and reported elsewhere $[19,20]$. Daily intakes of protein, total energy, and food groups were estimated from this BDHQ.

\section{Description of the main exposure variable}

Changes in POSS between the baseline and follow-up visits were categorized into five groups based on the score at both time points. These groups were used to specify the main exposure variables. Grouping by POSS changes were as follows: (i) Complete (remained in Group A)

(ii) Early change (Group A at baseline, but Group B at follow-up)

(iii) Moderate (remained in Group B)

(iv) Late change (Group B at baseline, but Group C at follow-up)

(v) Lost support (remained in Group C)

We defined the stages from (i) Complete to (ii) Early change as the Early lost stage and from (iii) Moderate to (iv) Late change as the Late lost stage.

\section{Description of outcome variables}

The rates of changes (\%) in protein intake, total energy intake, and BMI over 5 years were calculated for the outcome variables. The calculation method was as follows:

Rates of changes (\%)=each variable at the follow-up divided by each variable at the baseline multiplied by 100 .

A cut off threshold was applied for the median values and the outcome variables were divided into two groups. Protein intake was normalized to the total energy intake using the residual method. Grouping by our criteria was performed as follows:

(i) Sufficient: the rate of change for each outcome variable was greater than the median

(ii) Insufficient: the rate of change for each outcome variables was less than or equal to the median

We defined additional nutrition status for malnutrition evaluation as follows:

(i) Insufficient: the rates of changes for both protein intake and total energy intake for outcome variables were defined as IPE

(ii) Insufficient: the rates of changes for all three items (protein intake, total energy intake, and BMI) for the outcome variables were defined as IPEB

\section{Statistical analysis}

Characteristics at the baseline were compared between the male and female participants with paired-t-test and chi-square test. Intake of protein and total energy, BMI, and serum albumin level for each change in POSS at the baseline and follow-up visits were compared with ANOVA. Each change in POSS and the outcome variables between the Complete and Early change groups and between the Moderate and Late change groups were compared with the chi-squared test. Multivariable logistic regression analysis was used to examine the odds ratio of IPE and IPEB in the Early change group after adjustment for education (categories: years of schooling $\geq$ or $<9$ years), differences in ADL (TMIG index: continuous), and medical history (diabetes mellitus, hypertension, and renal disease; categories: Yes or No at follow-up). An $\alpha=0.05$ level was considered statistically significant for all analyses. The statistical software package STATA (version 13; Stata Corp., TX, USA) was used to perform all calculations and statistical analyses.

\section{Result}

Among the 600 original participants in the Niigata study, 193 individuals did not participate in the baseline assessment in 2003 for 
Citation: Nonomura A, Nohno K, Ogawa H (2019) Relationships between Changes in Posterior Occlusal Support Status and Risk of Proteinenergy Malnutrition among the Japanese Community-dwelling Elderly. Dentistry 9: 534. doi:10.4172/2161-1122.1000534

Page 3 of 7

the following reasons (refused, institutionalized, died, or moved out of Niigata city). During the baseline examinations, 34 individuals did not submit complete data in the dental examinations, questionnaire, anthropometric evaluations, and dietary assessment data. These individuals were excluded, leaving 373 individuals in the study. Five years later, follow up assessment was conducted and 88 individuals did not participate (refused, institutionalized, died, or moved out of Niigata city). Among the participants in the follow-up examinations, 13 individuals did not submit complete data in dental examinations, questionnaire, anthropometric evaluations, and dietary assessment, and were excluded. Finally, 272 individuals were included in the final analyses (Figure 1).

Table 1 presents the baseline characteristics of the subjects. Though there were no differences between the male and female participants in the prevalence of each POSS category, significant gender differences were detected in protein intake, total energy intake, BMI, and serum albumin level.

\begin{tabular}{|c|c|c|c|}
\hline Variable & Male & Female & $p$-value \\
\hline Number of subjects & 137 & 135 & - \\
\hline Age & 75 & 75 & - \\
\hline Number of remaining teeth & $16.6 \pm 9.51$ & $16.3 \pm 8.69$ & $0.759 \$$ \\
\hline Protein (g/day) & $77.2 \pm 12.6$ & $69.2 \pm 11.4$ & $0.0001 \$$ \\
\hline Total energy (kcal/day) & $2386.7 \pm 583.5$ & $1969.7 \pm 579.1$ & $0.0001 \$$ \\
\hline BMI & $22.7 \pm 2.72$ & $23.5 \pm 3.15$ & $0.042 \$$ \\
\hline Serum albumin (g/dL) & $4.07 \pm 0.232$ & $4.19 \pm 0.219$ & $0.0001 \$$ \\
\hline TMIG index & $12.0 \pm 1.16$ & $12.2 \pm 1.16$ & $0.184 \$$ \\
\hline History of diabetes mellitus & $10(38.5)$ & $16(61.5)$ & $0.201 \#$ \\
\hline History of hypertension & $49(51.6)$ & $46(48.4)$ & $0.770 \#$ \\
\hline History of renal disease & $3(75)$ & $1(25)$ & $0.321 \#$ \\
\hline \multicolumn{4}{|c|}{ The number of each category of POSS } \\
\hline Group A & $49(58.3)$ & $35(41.7)$ & $0.082 \#$ \\
\hline Group B & $36(41.4)$ & $51(58.6)$ & - \\
\hline Group C & $52(51.5)$ & $49(48.5)$ & - \\
\hline \multicolumn{4}{|l|}{$\$:$-test } \\
\hline
\end{tabular}

Table 1: Baseline characteristics of the subjects (Mean \pm SD, or $\mathrm{N}(\%)$ ).

Table 2 presents the means of protein and total energy intakes, BMI, and serum albumin level for each change in POSS at the baseline visit. There were no significant differences between the occlusal groups.

Table 3 presents the results of associations between the occlusal change groups and protein intake, total energy intake, BMI, IPE, and IPEB for each stage. The proportion of men with IPEB in the early change group was $40 \%$ and participants with no changes in occlusion in the Complete, Moderate, and Lost support groups comprised 9.7\%-14.3\%.

The proportion of men in the Early change group with insufficient protein intake, IPE, and IPEB was significantly higher than that in the Complete group ( $\mathrm{p}=0.035$ for protein intake, 0.007 for IPE, and 0.048 for IPEB). There were no significant associations in all items between the Moderate and Late change groups for men. For women, there were no associations between the changes in POSS and all malnutrition evaluations.

Table 4 presents the results of multivariable logistic regression analysis to examine the odds ratios of IPE and IPEB for men in the early change group after adjustment for education, differences in TMIG index, andmedical history (diabetes mellitus, hypertension, andrenal disease). Men in the Early change group had a significantly higher risk of IPE and IPEB (odds ratio: 4.0 for IPE and 4.3 for IPEB, $\mathrm{p}=0.045$ for both IPE and IPEB). Men in the Early change group had a significant decrease in their intake of vegetables and milk over 5 years $(\mathrm{p}<0.05)$ (Figure 2). 
Citation: Nonomura A, Nohno K, Ogawa H (2019) Relationships between Changes in Posterior Occlusal Support Status and Risk of Proteinenergy Malnutrition among the Japanese Community-dwelling Elderly. Dentistry 9: 534. doi:10.4172/2161-1122.1000534

1998: Niigata study was conducted

Niigata citizens, 70 years old were sent a written request to take part in the survey $(\mathrm{N}=4542)$

Subjects were selected randomly from several areas of Niigata $(\mathrm{N}=600)$

$$
\begin{array}{ll}
5 \text { years } \\
\text { Lost to follow up }(\mathrm{N}=193)
\end{array}
$$

2003: Baseline survey for this study

Medical and dental examinations, questionnaire, anthropometric evaluations, dietary assessment $(\mathrm{N}=407)$

1

$$
\text { Incomplete data }(\mathrm{N}=34)
$$

Study entrants ( $\mathrm{N}=373$ [male: 196 and female: 177])

5 years
Lost to follow up $(\mathrm{N}=88)$

2008: Follow-up survey for this study

Medical and dental examinations, questionnaire, anthropometric evaluations, dietary assessment $(\mathrm{N}=285)$

$$
\text { Incomplete data }(\mathrm{N}=13)
$$

Completed both baseline and follow-up examinations

\begin{tabular}{|c|c|c|c|c|c|c|c|c|c|}
\hline & $\mathbf{N}$ & Protein (g/day) & p-value* & Total energy (kcal/day) & p-value ${ }^{*}$ & BMI & p-value* & Serum albumin (g/dL) & $p$-value* \\
\hline \multicolumn{10}{|l|}{ Male } \\
\hline Complete & 39 & $78.5 \pm 11.5$ & N.S. & $2382.6 \pm 554.5$ & N.S. & $23.4 \pm 2.5$ & N.S. & $4.1 \pm 0.3$ & N.S. \\
\hline Early change & 10 & $70.3 \pm 6.0$ & & $2345.1 \pm 486.4$ & & $22.5 \pm 3.3$ & & $4.0 \pm 0.2$ & \\
\hline Moderate & 31 & $78.9 \pm 12.0$ & & $2272.3 \pm 412.2$ & & $22.9 \pm 2.6$ & & $4.1 \pm 0.2$ & \\
\hline Late change & 5 & $76.4 \pm 4.9$ & & $2478.7 \pm 458.8$ & & $22.8 \pm 0.7$ & & $4.1 \pm 0.3$ & \\
\hline Lost support & 52 & $76.5 \pm 14.7$ & & $2457.1 \pm 711.6$ & & $22.2 \pm 2.9$ & & $4.1 \pm 0.2$ & \\
\hline \multicolumn{10}{|l|}{ Female } \\
\hline Complete & 31 & $72.4 \pm 9.2$ & N.S. & $2063.5 \pm 500.1$ & N.S. & $22.8 \pm 3.0$ & N.S. & $4.2 \pm 0.2$ & N.S. \\
\hline Early change & 4 & $61.4 \pm 8.5$ & & $1649.2 \pm 304.7$ & & $24.3 \pm 2.2$ & & $4.1 \pm 0.1$ & \\
\hline Moderate & 41 & $69.3 \pm 12.2$ & & $1995.0 \pm 618.5$ & & $23.1 \pm 3.1$ & & $4.2 \pm 0.2$ & \\
\hline Late change & 10 & $64.1 \pm 6.5$ & & $1868.5 \pm 513.3$ & & $23.9 \pm 2.3$ & & $4.2 \pm 0.3$ & \\
\hline Lost support & 49 & $68.7 \pm 12.4$ & & $1936.0 \pm 622.9$ & & $24.1 \pm 3.5$ & & $4.2 \pm 0.2$ & \\
\hline \multicolumn{10}{|l|}{ *: ANOVA } \\
\hline
\end{tabular}

(Study participants $\mathrm{N}=272$ [male: 137 and female: 135])

Participants $/$ Entrants $=72.9 \%$

Figure 1: Overview of the recruitment of participants for this study.

Table 2: Intake of protein and total energy, BMI and serum albumin in each occlusal change groups at baseline (Mean \pm S.D.). 
Citation: Nonomura A, Nohno K, Ogawa H (2019) Relationships between Changes in Posterior Occlusal Support Status and Risk of Proteinenergy Malnutrition among the Japanese Community-dwelling Elderly. Dentistry 9: 534. doi:10.4172/2161-1122.1000534

Page 5 of 7

\begin{tabular}{|c|c|c|c|c|c|c|c|c|c|c|c|}
\hline \multirow{2}{*}{$\begin{array}{l}\text { Stage of } \\
\text { changes }\end{array}$} & \multirow{2}{*}{$\begin{array}{l}\text { POSs } \\
\mathrm{N}\end{array}$} & \multicolumn{2}{|l|}{ Protein } & \multicolumn{2}{|l|}{ Total energy } & \multicolumn{2}{|l|}{ BMI } & \multicolumn{2}{|l|}{ IPE } & \multicolumn{2}{|l|}{ IPEB\# } \\
\hline & & $\begin{array}{l}\text { Insufficient } \mathbf{N} \\
(\%)\end{array}$ & $\begin{array}{l}\text { p- } \\
\text { value }^{*}\end{array}$ & $\begin{array}{l}\text { Insufficient } N \\
(\%)\end{array}$ & $\begin{array}{l}\text { p- } \\
\text { value* }\end{array}$ & $\begin{array}{l}\text { Insufficient N } \\
(\%)\end{array}$ & \begin{tabular}{|l} 
p- \\
value
\end{tabular} & $\begin{array}{l}\text { Insufficient } \mathrm{N} \\
(\%)\end{array}$ & $\begin{array}{l}\text { p- } \\
\text { value* }\end{array}$ & $\begin{array}{l}\text { Insufficient } \mathbf{N} \\
(\%)\end{array}$ & $\begin{array}{l}\text { p- } \\
\text { value* }\end{array}$ \\
\hline \multicolumn{12}{|l|}{ Male } \\
\hline Complete & 39 & $13(33.3)$ & 0.035 & $18(46.2)$ & 0.056 & $21(53.8)$ & 0.727 & $7(17.9)$ & 0.007 & $5(12.8)$ & 0.048 \\
\hline Early change & 10 & $7(70.0)$ & - & $8(80.0)$ & - & $6(60.0)$ & - & $6(60.0)$ & - & $4(40.0)$ & - \\
\hline Moderate & 31 & $17(54.8)$ & 0.148 & $20(64.5)$ & 0.845 & $13(41.9)$ & 0.935 & $12(38.7)$ & 0.088 & $3(9.7)$ & 0.468 \\
\hline Late change & 5 & $1(20.0)$ & - & $3(60.0)$ & - & $2(40.0)$ & - & $0(0)$ & - & $0(0)$ & - \\
\hline Lost support & 52 & $24(46.2)$ & - & $28(53.8)$ & - & $23(44.2)$ & - & $16(30.8)$ & - & 10(19.2) & - \\
\hline \multicolumn{12}{|l|}{ Female } \\
\hline Complete & 31 & $16(51.6)$ & 0.051 & $19(61.3)$ & 0.167 & $13(41.9)$ & 0.212 & $10(32.3)$ & 0.179 & $4(12.9)$ & 0.445 \\
\hline Early change & 4 & $0(0)$ & - & $1(25.0)$ & - & $3(75.0)$ & - & $0(0)$ & - & $0(0)$ & - \\
\hline Moderate & 41 & $21(51.2)$ & 0.099 & $14(34.1)$ & 0.728 & $23(56.1)$ & 0.423 & $6(14.6)$ & 0.253 & $5(12.2)$ & 0.847 \\
\hline Late change & 10 & $8(80.0)$ & - & $4(40.0)$ & - & $7(70.0)$ & - & $3(30)$ & 0.353 & $1(10.0)$ & - \\
\hline Lost support & 49 & $29(59.2)$ & - & 21(42.9) & - & $25(51.0)$ & - & $15(30.6)$ & - & $7(14.3)$ & - \\
\hline $\begin{array}{l}\text { \$IPE: Both of } \\
\text { \#IPEB: All of } t \\
{ }^{*} \text { chi-square te }\end{array}$ & $\begin{array}{l}\text { rotein al } \\
\text { ree item } \\
t\end{array}$ & $\begin{array}{l}\text { nd total energy int } \\
s \text { (protein, total en }\end{array}$ & $\begin{array}{l}\text { ake } \\
\text { ergy and }\end{array}$ & & & & & & & & \\
\hline
\end{tabular}

Table 3: Association between the changes of POSS and insufficient protein intake, total energy intake and BMI and IPE and IPEB.

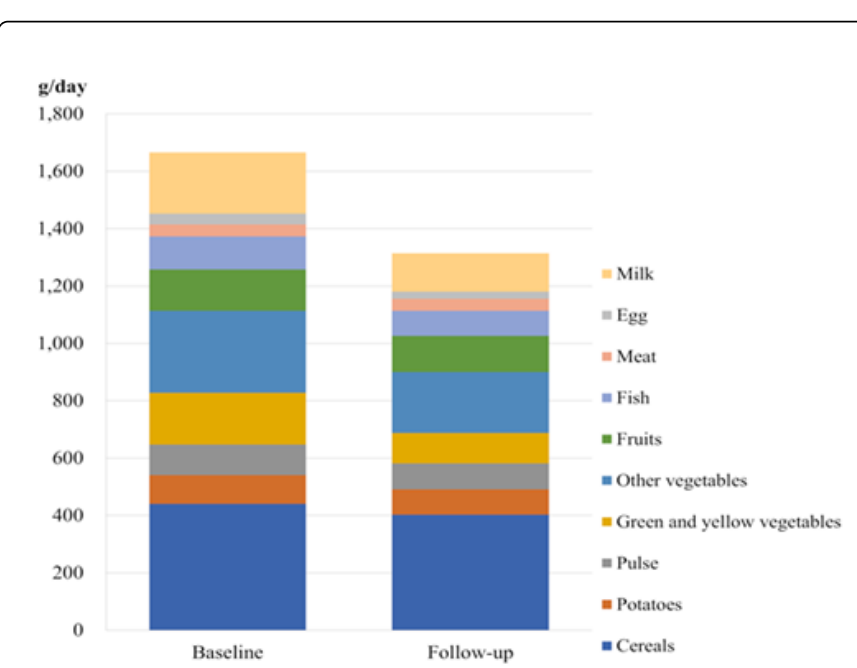

Figure 2: Intakes of green and yellow vegetables, other vegetables, and milk significantly decreased over 5 years in the male Early change group $(\mathrm{p}<0.05)$. Egg intake also decreased $(\mathrm{p}=0.055)$. These $\mathrm{p}$-values were from the paired-t-test.

\begin{tabular}{|l|l|l|l|l|l|}
\hline \multirow{2}{*}{$\begin{array}{l}\text { Independent } \\
\text { variable }\end{array}$} & Crude & & Adjusted & & p-value \\
$\begin{array}{l}\text { Protein + Total energy } \\
\text { (IPE) }\end{array}$ & odds ratio & $\mathbf{9 5 \%} \mathbf{C l}$ & odds ratio & $\mathbf{9 5 \%} \mathbf{C I}$ & \\
\hline $\begin{array}{l}\text { Early change and ref: } \\
\text { others }\end{array}$ & 3.9 & $1.1-14$. & 4 & $\begin{array}{l}1.0-15 . \\
6\end{array}$ & 0.045 \\
\hline $\begin{array}{l}\text { Protein + Total energy } \\
\text { + BMI (IPEB) }\end{array}$ & & & & & \\
\hline $\begin{array}{l}\text { Early change and ref: } \\
\text { others }\end{array}$ & 4 & $1.0-15$. & 4.3 & $\begin{array}{l}1.0-17 . \\
6\end{array}$ & 0.045 \\
\hline $\begin{array}{l}\text { \$: adjusted for education, difference of TMIG index and medical history } \\
\text { (diabetes mellitus, hypertension and renal disease) }\end{array}$ \\
\hline
\end{tabular}

Table 4: Multivariable logistic regression analysis to examine the odds ratio of PE and PEM in male early change group.

\section{Discussion}

The current study assessed the relationship between POSS and protein intake, total energy intake, and BMI based on the status of PEM in independent community-dwelling elderly individuals. The results showed that changes in nutrition intake and BMI over 5 years were relatively small because our subjects were generally active and living independently. Indeed, changes in serum albumin level could not be used to determine malnutrition (PEM) because the levels at the baseline and follow-up visits hardly changed. Thus, we defined two 
Citation: Nonomura A, Nohno K, Ogawa H (2019) Relationships between Changes in Posterior Occlusal Support Status and Risk of Proteinenergy Malnutrition among the Japanese Community-dwelling Elderly. Dentistry 9: 534. doi:10.4172/2161-1122.1000534

Page 6 of 7

criteria for malnutrition: IPE: a decline in nutrition intake, and IPEB: a decline in BMI with poor nutrition intake. In our study, there were also significant differences between men and women in protein intake, total energy intake, BMI, and serum albumin level at the baseline, in agreement with previous reports indicating that nutrition intakes differed by gender [21-24]. Consequently, we assessed the relationships between changes in POSS and malnutrition by gender.

According to Bianchetti A, et al. poor nutrition intake was correlated with socioeconomic conditions, functional level, and effective status [25]. Thus, we selected education levels, TMIG index, and medical history as covariates for multiple logistic regression models to assess the associations between changes in POSS and each malnutrition criterion. The odds ratios of IPE and IPEB adjusted for these covariates were 4.0 and 4.3 , respectively, for men in the early change group compared to the other groups. Additionally, the intake of green and yellow vegetables, other vegetables, and milk decreased significantly in the male Early change group $(p<0.05)$ along with egg consumption $(\mathrm{p}=0.055)$ (Figure 2). Yamashita $M$ reported that for elderly men living alone, the frequency of intake of cereals, vegetables, and green-yellow vegetables was significantly lower and the intake of fats and oils was significantly higher than for men in a couple household [23]. Although the current study did not ask whether family members were living together, the reduction of vegetable and greenyellow vegetable intake in elderly men showed a similar tendency.

It was also noteworthy that significant differences in IPE and IPEB were only found in Early lost stage male participants. The early stage of POSS loss might be considered a risk factor of malnutrition for men. Yoshiba K, et al. reported that the diversity of food intake for men decreased more than that for women, and the risk of malnutrition was a concern for men [24]. Many elderly men living alone experience loneliness due to an inability to communicate with their community [23], which might affect their unbalanced food intake. Based on these findings, elderly men may have a higher risk of malnutrition and difficulties adapting to environmental changes. Changes in POSS might be related to environmental changes and may increase the risk of malnutrition in the early change group. However, our data for the late lost stage did not show an increment of malnutrition and we failed to confirm the causality.

The Ministry of Health, Labor, and Welfare in Japan indicated that motivation, knowledge, and behavior modification skills are necessary for the elderly to prevent malnutrition and maintain their health [26]. Therefore, to prevent tooth loss, nutritional instructions might be essential for the elderly who may have lost posterior OSZ in the early stage.

There is a limitation to this study. Although determinants related to food intake other than dentition statuses, such as nutritional knowledge, cooking skills, presence or absence of people living with the participants, and abnormality of oral function are important [27], we failed to present such data assessment in our current results. We are conducting further surveys on the condition including the above determinants after 10 years for subjects with a high tendency of malnutrition.

\section{Conclusion}

Our findings suggested that elderly men in the early stage of losing POSS exhibited lower protein intake and increased malnutrition.

\section{Acknowledgment}

We greatly appreciate all the Niigata study participants. This work was supported by Grant-in-Aid from the Ministry of Health, Labor, and Welfare of Japan (H10-Iryo-001, H13-Iryo-001, and H16Iryo-020) and Japan Society for the Promotion of Science KAKENHI (26861827).

\section{References}

1. Visvanathan R, Macintosh C, Callary M, Penhall R, Horowitz M, et al. (2003) The nutritional status of 250 older Australian recipients of domiciliary care services and its association with outcomes at 12 months. J Am Geriatr Soc 51: 1007-1011.

2. Neumann SA, Miller MD, Daniels L, Crotty M (2005) Nutritional status and clinical outcomes of older patients in rehabilitation. J Hum Nutr Dietet 18: 129-136.

3. Guigoz Y, Lauque S, Vellas BJ (2002) Identifying the elderly at risk for malnutrition. The mini nutritional assessment. Clin Geriatr Med 18: 737-757.

4. Agarwal E, Miller M, Yaxley A, Isenring E (2013) Malnutrition in the elderly: a narrative review. Maturitas 76: 296-302.

5. Sheiham A, Steele JG, Marcenes W, Lowe C, Finch S, et al. (2011) The relationship among dental status, nutrient intake, and nutritional status in older people. J Dent Res 80: 408-413.

6. Hung HC, Willett W, Ascherio A, Rosner BA, Rimm E, et al. (2003) Tooth loss and dietary intake. J Am Dent Assoc 134: 1185-1192.

7. Nowjack-Raymer RE, Sheiham A (2007) Numbers of natural teeth, diet, and nutritional status in US adults. J Dent Res 86: 1171-1175.

8. Joshipura KJ, Willett WC, Douglass CW (1996) The impact of edentulousness on food and nutrient intake. J Am Dent Assoc 127: 459-467.

9. Yamauchi T, Koide A (2008) The relationship between masticatory ability and dietary intake in elderly. Nagoya Women's University Bulletin No. 54 89-98.

10. Yoshihara A, Watanabe R, Hanada N, Miyazaki H (2009) A longitudinal study of the relationship between diet intake and dental caries and periodontal disease in elderly Japanese subjects. Gerodontology 26: $130-136$.

11. Kikutani T, Yoshida M, Enoki H, Yamashita Y, Akifusa S, et al. (2012) Relationship between nutrition status and dental occlusion in community-dwelling frail elderly people. Geriatr Gerontol Int 13: 50-54.

12. Tada S, Ikebe K, Kamide K, Gondo Y, Inomata C, et al. (2017) Relationship between atherosclerosis and occlusal support of natural teeth with mediating effect of atheroprotective nutrients: From the SONIC study. PLoS ONE 12: e0182563.

13. Österberg T, Steen B (1982) Relationship between dental state and dietary intake in 70-year-old males and females in Göteborg, Sweden: a population study. J Oral Rehabil 9: 509-521.

14. Sahyoun NR, Lin CL, Krall E (2003) Nutritional status of the older adult is associated with dentition status. J Am Diet Assoc 103: 61-66.

15. Yoshida M, Kikutani T, Yoshikawa M, Tsuga K, Kimura M, et al. (2011) Correlation between dental and nutritional status in community-dwelling elderly Japanese. Geriatr Gerontol Int 11: 315-319.

16. Kuzuya M (2013) Nutrition. Nihon Ronen Igakkai Zasshi 50: 46-48.

17. Ikebe K, Matsuda K, Kagawa R, Enoki K, Okada T, et al. (2012) Masticatory performance in older subjects with varying degrees of tooth loss. J Dent 40: 71-76.

18. Eichner K (1955) Uber eine Gruppeneinteilung der Lunckengebisse fur die Prothetic. Dtsch Zahnarztl Z 10, 1831-1834.

19. Kobayshi S, Murakami K, Sasaki S, Okubo H, Hirota N, et al. (2011) Comparison of relative validity of food group intakes estimated by comprehensive and brief-type self-administered diet history questionnaires against $16 \mathrm{~d}$ dietary records in Japanese adults. Public Health Nutr 14: 1200-1211. 
Citation: Nonomura A, Nohno K, Ogawa H (2019) Relationships between Changes in Posterior Occlusal Support Status and Risk of Proteinenergy Malnutrition among the Japanese Community-dwelling Elderly. Dentistry 9: 534. doi:10.4172/2161-1122.1000534

Page 7 of 7

20. Kobayashi S, Honda S, Murakami K, Sasaki S, Okubo H, et al. (2012) Both comprehensive and brief self-administered diet history questionnaires satisfactorily rank nutrient intakes in Japanese adults. J Epidemiol 22: 151-159.

21. Ministry of Health, Labor and Welfare. National Health and Nutrition Survey.

22. Suzuki A, Watanabe T, Watanabe R, Nakaji K, Mitsuda H, et al. (2015) Actual food group and nutrient intake by independent-living elderly individuals as assessed via meal weighing method. Journal for the Integrated Study of Dietary Habits 25: 259-269.

23. Yamashita M (2011) The dietary habits of different households among elderly persons-Characteristic of male elderly persons living alone- Bull. Kagoshima Pref, College, 62: 47-62.
24. Yoshiba K, Takemi Y, Ishikawa M, Yokoyama T, Nakaya T, et al. (2015) Relationship between dietary diversity and food access among elderly living alone in Saitama Prefecture. Japanese Journal of Public Health 62: 707-718.

25. Bianchetti A, Rozzini R, Carabellese C, Zanetti O, Trabucchi M (1990) Nutritional intake, socioeconomic conditions, and health status in a large elderly population. J Am Geriatr Soc 38: 521-526.

26. Ministry of Health, Labor and Welfare. Practical training instructor training material of specific health guidance.

27. Nicklett EJ, Kadell AR (2013) Fruit and vegetable intake among older adults: a scoping review. Maturitas 75: 305-312. 